\title{
Modeling passenger flows in public transport stations ${ }^{1}$
}

\author{
Cem Kırlangıçoğlu ${ }^{2}$
}

\begin{abstract}
There are many architectural design parameters for public transport stations which include urban and station level studies. Each station must be designed in accordance with the basic passenger requirements such as accessibility, safety, comfort, satisfaction and etc. Circulation spaces must be formed and sized to meet the minimum movement needs of passengers. For an underground station; main entrance region, position of gates, location and number of turnstiles, escalators, stairs, ramps, passageways, intermediate concourses and platforms must be arranged to minimize walking distances and to prevent congestion. In this study, circulation of passengers is simulated in a quantitatively verifiable manner, taking into account how individuals interact with each other and with the physical obstacles in their environment in a metro station. Virtual experiments are performed to see the continuity and density of pedestrian flow at different levels of Haram Area East Metro Station of the first metro line of Madinah Al-Munawwarah, Saudi Arabia. According to the predictions, more than 40.000 passengers are expected to use this station in one hour after a Friday prayer during Ramadan period in the year of 2040. That means a critically high travel demand and it is really significant to design the most convenient underground station for these passengers to fulfil the necessary requirements.
\end{abstract}

Keywords: Passenger Flow, Station Capacity Analysis, Pedestrian Simulation; Underground Station; Madinah Al-Munawwarah, Saudi Arabia.

\section{Introduction}

Madinah is the $2^{\text {nd }}$ holy city in Islam, and the $1^{\text {st }}$ capital of the Islamic civilization. It was the home of the Prophet Mohammed and his burial place. Based on this rich heritage, history, and past prominence it became a magnet for billions of Muslims and affection and the source of their knowledge and civilization. Growing demand from residents and visitors Madinah's population has recently crossed the 1 million mark and is officially the 4th largest city in Saudi Arabia, growing ahead of the national average at around 3.4\% per year and expected to double in the next 20 years. On the other hand, around 6-8 million Muslims visit Madinah every year, and the number is expected to reach 34 Million by 2024 (KEC, 2012). The Saudi Arabian government has planned an

\footnotetext{
1 The data used in this paper is collected and analyzed as a part of "Consulting Services for the Public Transport System of Madinah Al-Munawwarah and Preliminary Design of the Metro Project" conducted by Istanbul Ulasim AS.

${ }^{2}$ Ph.D., Istanbul University, Institute of Social Sciences, Department of Geography, cemkirlangicoglu@gmail.com
} 
Kırlangıçoğlu, C. (2015). Modeling passenger flows in underground stations. International Journal of Human Sciences, 12(1), 1485-1500. doi: $10.14687 /$ ijhs.v12i1.3275

initiated many development projects to cater to the growing demand in all sectors, especially transportation, amongst residents and visitors. One of the most significant projects is the Madinah Al Munawwarah 'Metro Line 1' which is designed between Miqat and the Prince MBA Airport. The $34 \mathrm{~km}$ length alignment passes through the six major attraction points in the city which are Miqat Mosque, King Abdullah Pilgrim City (KAPC), Haram Area, Knowledge Economic City (KEC), Haramain High Speed Rail (HHRS) and the Prince MBA Airport. In total, there are 23 stations on the line. This study concerns about simulating the passenger flow in the $10^{\text {th }}$ station of Metro Line 1 which is also called as Haram Area East Station because of its location at east side next to Masjid Al Nabawi (The Prophet's Mosque).

\section{The Purpose of the Study}

Special travel demand conditions may occur as a result of events such as large public meetings in city centers, sport attractions, holiday celebrations and etc. crowded activities. For such events, the system is expected to run at full capacity conditions; therefore in the Holy City of Madinah, the Metro Line 1 operation plans need to be developed alternatively on an individual basis for Haram stations. There are 2 stations next to Masjid Al Nabawi, East and West metro stations. This study deals with the East one. The aim of this study is to simulate realistic passenger circulation of the Haram Area East Station as designed in architectural layouts in order to maximize anticipation of potential issues regarding pedestrian flows. The continuity, density and speed characteristics of passengers have been tested through a pedestrian simulation process. Through the process, problematic areas of each alternative design have been detected and the necessary architectural revisions were prepared. This study shows the pedestrian simulation results of final design which has been prepared after testing many alternative station designs and pedestrian circulation scenarios. The following methodology has been followed all through the application process.

\section{Methodology}

In the study of Abdelgawad et al. (2012), it was concluded that after the Friday prayer during Ramadan, Masjid Al Nabawi has the highest number of people. Mainly, the peak period is the first quarter and then the passengers gradually leave after the Friday prayer. The arrival profile of the hourly pedestrian flow is shown in Figure 1. In addition, pedestrian speed follows a normal distribution with a maximum value of $1.3 \mathrm{~m} / \mathrm{s}$ and a standard deviation of $0.25 \mathrm{~m} / \mathrm{s}$ around the Haram area. Passengers prefer to walk in accordance with the least effort principle including shortest time instead of shortest path. 


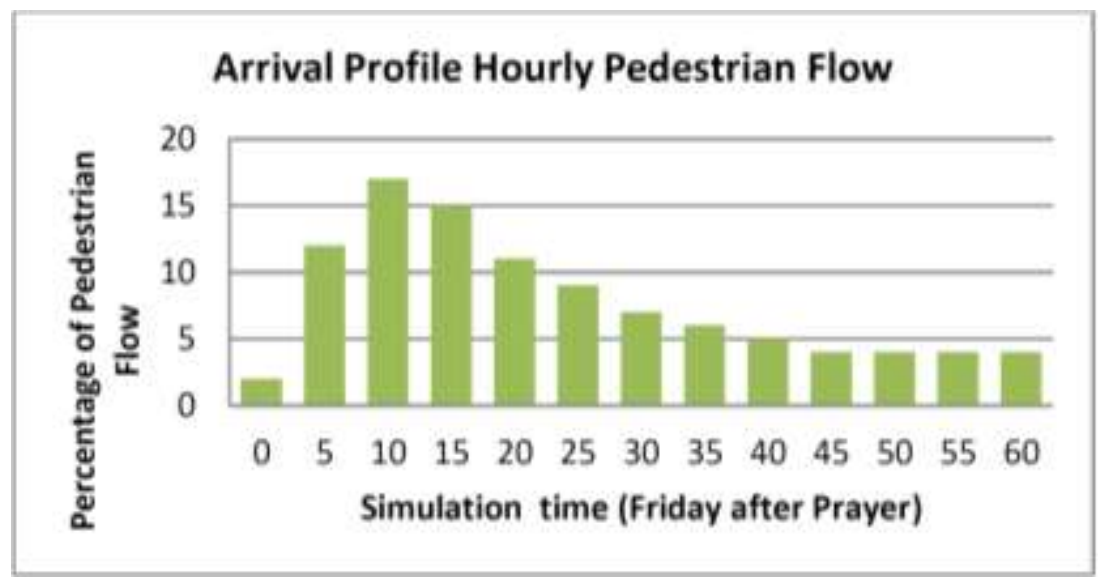

Figure 1: Hourly pedestrian flow of the arrival profile after Friday prayer during Ramadan In "Crowd Risk Analysis and Crowd Safety" article (2013), Prof. Dr. G. Keith Still says that crowds have their own specific dynamics. Local characteristics of the crowds, their speed, group movements, route selection methodologies and space utilization behaviors must be well analyzed for realistic simulation results. Then, circulation spaces must be formed and sized to meet the passengers' movement needs. All circulation paths must be obstruction-free as much as possible for a continuous and fluent passenger circulation through the station. Overground main entrance region, position of entrance gates, location of turnstiles, escalators, stairs, ramps, passageways, intermediate concourses and platforms must be arranged to minimize walking distances and to prevent congestion. Through the passenger flow simulation process, one of the main references was a report about "Managing Large Events and Perturbations at Stations - Pedestrian Flow Modeling Process Definition" which was prepared by Rail Safety \& Standards Board (2004). It gives some basic criteria to understand the behavior of people while preparing the station design parameters. The details will not be given here but according to the report, the most important behavior influencing factors affecting the passenger movement are environment, physical layout, information, movement, communication and individual factors of people.

After preparing all the necessary data and defining the passenger simulation criteria, the next step is to use pedestrian simulation software for the design assessment of the underground station. LEGION Spaceworks software has been used all through the study. According to the producer, Legion Ltd. (2015), the simulation model of the software does not contain any unsubstantiated analogies, it incorporates intuitive appeal: the pedestrians move on the principle of 'least effort'. Each chooses its next step in an effort to find the best compromise between directness of path, speed and comfort. These decisions take into account a passenger's preferences and objectives as well as the context, environment and other pedestrians around them. The software uses a 'microscopic' simulation model, which treats space as a continuum, using Spatial Objects 
Kırlangıçoğlu, C. (2015). Modeling passenger flows in underground stations. International Journal of Human Sciences, 12(1), 1485-1500. doi: $10.14687 /$ ijhs.v12i1.3275

(Entrances, Exits, Escalators, etc.) to define space utilization. The model incorporates Entity Profiles drawn from empirical data. Ultimately, crowd behavior emerges 'naturally' rather than through 'hard-coding'. This approach accommodates the variations, choices and chance events that characterize pedestrian movement in everyday life. Pedestrian areas design involve calculation of "levels of service" corresponding to pedestrian density scales, the most common ones being Fruin (1971) scales given in Figure 2.

\begin{tabular}{|c|c|c|c|}
\hline \multirow{2}{*}{$\begin{array}{c}\text { Fruin's Level } \\
\text { of Service }\end{array}$} & \multicolumn{3}{|c|}{ Average area module } \\
\cline { 2 - 4 } & $\begin{array}{c}\text { Walkway } \\
{\left[\mathrm{m}^{2} / \mathrm{ped}\right]}\end{array}$ & $\begin{array}{c}\text { Stairs } \\
{\left[\mathrm{m}^{2} / \mathrm{ped}\right]}\end{array}$ & $\begin{array}{c}\text { Queue } \\
{\left[\mathrm{m}^{2} / \mathrm{ped}\right]}\end{array}$ \\
\hline A & $>3.24$ & $>1.85$ & $>1.21$ \\
\hline B & $3.24-2.32$ & $1.85-1.39$ & $1.21-0.93$ \\
\hline C & $2.32-1.39$ & $1.39-0.93$ & $0.93-0.65$ \\
\hline D & $1.39-0.93$ & $0.93-0.65$ & $0.65-0.28$ \\
\hline E & $0.93-0.46$ & $0.65-0.37$ & $0.28-0.19$ \\
\hline F & $<0.46$ & $<0.37$ & $<0.19$ \\
\hline
\end{tabular}

Figure 2: Fruin's Level of Service Hierarchy (Fruin, 1971)

\section{Pedestrian Simulation Results}

One of the most important projects in Madinah is the Haram Expansion Project. Haram serves near 700.000 people today and it is planned to increase this number to 1.6 million. The location of the East Metro Station in accordance with Masjid Al Nabawi and 2040 expansion plan of Haram Area is given in Figure 3.

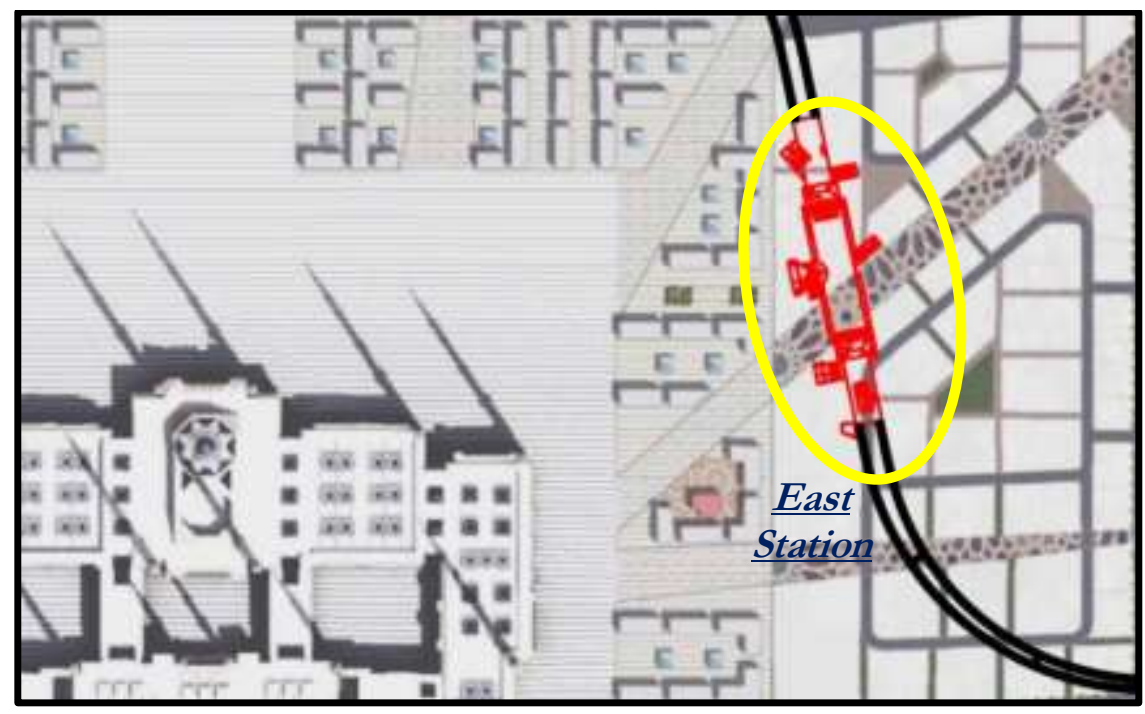

Figure 3: Location of Haram East Station 
Haram area ridership forecasts show that the highest travel demand will occur in Ramadan High Peak time when the passenger numbers for the $10^{\text {th }}$ station will be like in Table 1.

Table 1: Ridership forecasts for Haram Area - East Station

\begin{tabular}{|c|c|c|c|c|c|}
\hline & & & Direction & Board & Alight \\
\hline \multirow{2}{*}{ 茪 } & \multirow{2}{*}{\multicolumn{2}{|c|}{ 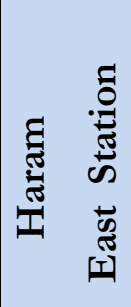 }} & ( To Miqat ) & $\begin{array}{c}8.143 \\
(19.25 \%)\end{array}$ & $\begin{array}{l}2.028 \\
(38 \%)\end{array}$ \\
\hline & & & ( To Airport) & $\begin{array}{c}34.149 \\
(80.75 \%)\end{array}$ & $\begin{array}{l}3.330 \\
(62 \%)\end{array}$ \\
\hline
\end{tabular}

According to Table 1;

- 34,149 passengers per hour (pph) get on the train at Station 10 to go to the Airport direction. This number is $80.75 \%$ of total boarding from this station

- 3,330 pph get off the train at Station 10 towards Airport direction

- 8,143 pph get on the train at Station 10 to go to the Miqat direction. This number is $19.25 \%$ of total boarding from this station

- 2,028 pph get off the train at Station 10 towards Miqat direction

Some general rules and presuppositions are given below:

- The pedestrians move on the principle of 'least effort'. Each chooses its next step in an effort to find the best compromise between directness of path, speed and comfort. These decisions take into account a passenger's preferences and objectives as well as the context, environment and other pedestrians around them.

- The number of alighting passengers is very low, so they will be ignored during the simulation.

- Headway is 90 seconds.

- Train doors will remain open for 30 seconds for boarding passengers

- Boarding will be available for both sides of the train at the same time. One side is for families, handicapped and elderly people while the other side is for other passengers.

- Delay time of passengers at turnstiles is 2 seconds. 
Kırlangıçoğlu, C. (2015). Modeling passenger flows in underground stations. International Journal of Human Sciences, 12(1), 1485-1500. doi: $10.14687 /$ ijhs.v12i1.3275

\subsection{Main Entrance Area}

According to general station design principles all through the Metro Line 1, all entrances of stations must be noticeable, visually appealing, and easily accessible. They contain numerous vertical circulation elements such as stairs, elevators, and escalators. Capacity of entrances and total number of turnstiles must be enough to handle peak hour circulation, special event circulation, and emergency situation. Entrances should have enough capacity to accommodate expected passenger volume to fulfill the requirement of NFPA 130 and local Civil Defense.

Totally 42,292 people are expected to come from Haram Area to the East metro station after Friday prayer during Ramadan in 2040. There are mainly 8 entrance zones to welcome the passengers. Directions of entrances are mainly positioned as looking to the West side to encounter the passengers coming from the Masjid. Just three entrances are not located in accordance with this criterion because of architectural restrictions, but these entrances will be used by passengers coming from East side in normal operation time. In addition, these entrances will be very helpful to serve passengers coming from other congested gates on peak period.

The whole entrance region has high potential of being congested in general because of too many pedestrians coming to the metro station in a very short time, but the incoming passengers are distributed to 8 entrances to prevent congestion. Passengers will use the nearest entrances first. If an entrance begins to become congested, the signage and the staff will help to orientate the people to more suitable entrances.

The station has totally 68 escalators and 62 elevators in addition to the stairs. The entrance region with eight main entrances has 40 escalators and 38 elevators to meet the requirements of arriving passengers. There are 155 turnstiles distributed to eight main entrance zones including gates. Each gate has a specific name. Figure 4 shows the 8 main entrance zones and name of their gates. In the figure, the letter of ' $\mathbf{A}$ ' indicates Airport direction entrance directly going to the $1^{\text {st }}$ concourse floor, while the letter of ' $\mathbf{M}$ ' indicates the Miqat direction entrance directly going to the $2^{\text {nd }}$ concourse floor. In addition; ' $\mathbf{F}$ ' letter indicates family entrances for both Airport and Miqat direction travels. ' $\mathrm{F}-\mathrm{A}$ ' is for the families going to Airport direction while ' $\mathrm{F}-\mathrm{M}$ ' is for the families going to Miqat direction. There are 2 family entrances including totally 3 different gates. However these entrances are mainly designed for use of families, disabled and elderly people will also be able to use them. In this way they will have a fast access to the train, and they will not affect the fluency of general passenger circulation. 


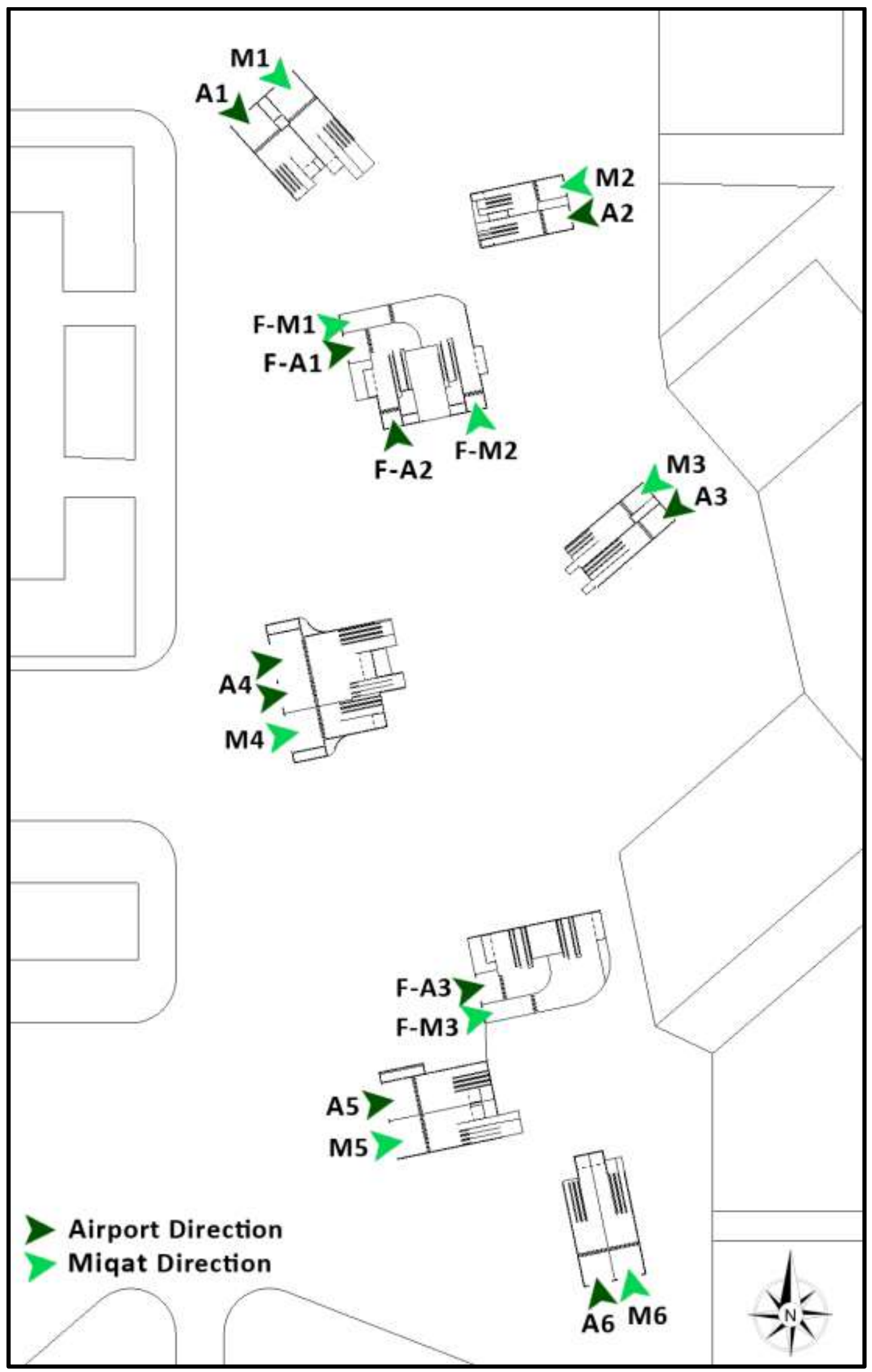

Figure 4: Location of Main Entrances of the Haram East Station 
Kırlangıçoğlu, C. (2015). Modeling passenger flows in underground stations. International Journal of Human Sciences, 12(1), 1485-1500. doi: $\underline{10.14687 / \text { ijhs.v12i1.3275 }}$

The passenger flow simulation results of the main entrance region are given in Figure 5.

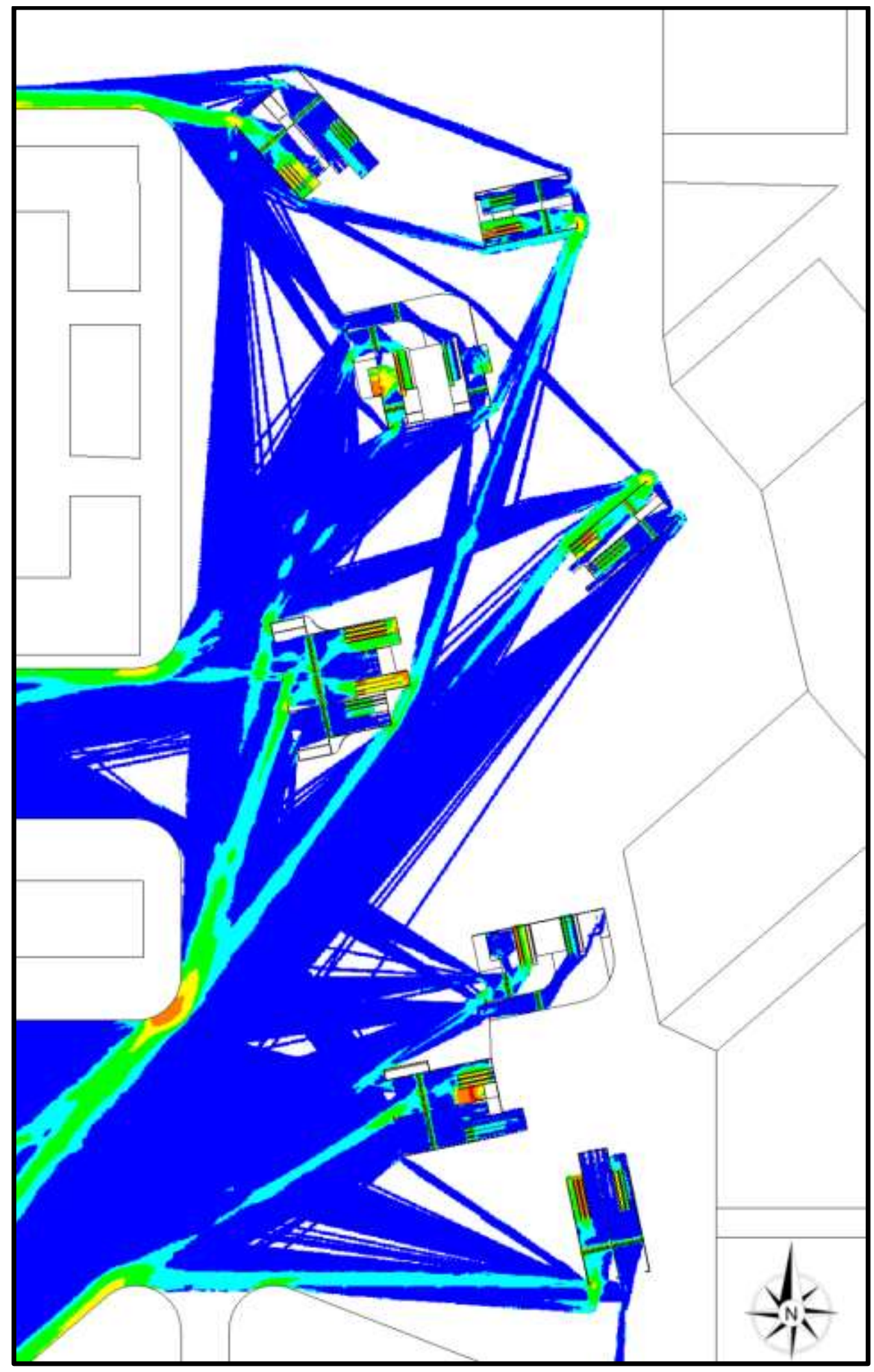

Figure 5: Passenger Density at Main Entrances

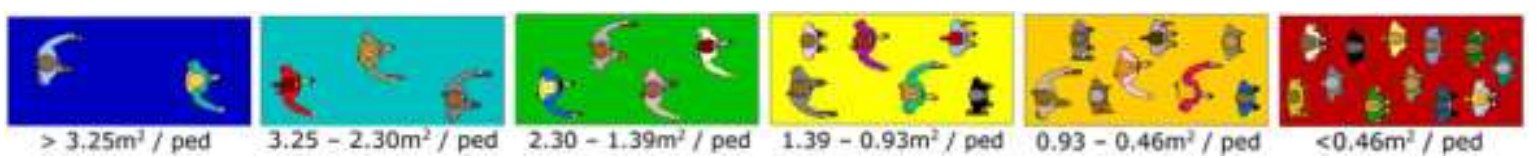


Kırlangıçoğlu, C. (2015). Modeling passenger flows in underground stations. International Journal of Human Sciences, 12(1), 1485-1500. doi: $10.14687 /$ ijhs.v12i1.3275

The simulation results show that; the main entrance region does not have any serious or dangerous problem about passenger circulation and flow in general. Even if A1/M1 entrance is one of the densest gates, it does not have any problem about circulation. A2/M2 entrance is far away from the Haram area. In normal period, these gates are not expected to have high number of passengers but in peak period it will be different because of fact that the entrances near to the Haram area will be crowded and therefore people will prefer other entrances to avoid from the crowd.

In addition, the officials on site will direct passengers from crowded entrances to more available gates such as A2 and M2 gates. A3 and M3 gates are also far away from Haram area and expected to have too low passenger numbers in general. But in the peak period, people avoiding from too crowded areas and long waiting times are expected to choose the gates having lowest density. Passengers have to make a U-Turn movement because of architectural restrictions of this entrance but it does not cause a serious problem at the entrance in general.

The family entrances are used by both disabled and elderly people in addition to the families, so they have high number of passengers, too. The simulation results show that, the northbound family entrance has a fluent passenger circulation and no problematic areas. Just in front of the elevators a medium density occurs but it is because of the choice of passengers who prefer waiting the elevators rather than spending time by a few escalators until the platform. In addition, one of the escalators has orange color. Like elevators, this is also not problematic because people standing on the escalator densely but they move to the lower floor. That means there is a fluent density that is all right in the manner of simulation.

The most crowded gate is A4 at West direction of entrance region. The gate directly faces the passengers coming from Haram area. The Airport side of this entrance includes more escalators and elevators than the Miqat side to meet the necessary requirements to meet the requirements in accordance with the demand. A4 and M4 entrances have the highest passenger demand as a result of their position in accordance with the Haram area. Nevertheless, they have no red colored or dangerous areas because of the high capacity of their escalators and elevators.

Simulation output of another dense entrance, which is at the Southwest side of entrance region, is A5/M5 entrance facing the passengers directly like the A4/M4 entrance and having higher demand values than normal. There is a red and orange colored area in front of an elevator at this entrance. It does not indicate any danger because it is a queue area and people just stand closely to each other. According to Fruin's LOS standards for queue regions, these kinds of areas are safe for passengers. 
Kırlangıçoğlu, C. (2015). Modeling passenger flows in underground stations. International Journal of Human Sciences, 12(1), 1485-1500. doi: $10.14687 /$ ijhs.v12i1.3275

According to the simulation results of A6 and M6 gates, this entrance does not have a circulation or density problem, too. The gates are directed to South side, so passengers have to make a turn movement to enter into the entrances. This causes a medium level density especially at A6 entrance but it does not indicate any danger.

Table 2 shows number of passengers passing through each gate of the station.

Table 2: Cumulative passenger count for each gate

\begin{tabular}{|c|c|c|c|c|}
\hline Gate Name & Passenger Count & & Gate Name & Passenger Count \\
\hline A1 & 4292 & & M3 & 883 \\
\hline M1 & 1161 & & A4 & 9359 \\
\hline A2 & 3147 & & M4 & 1285 \\
\hline M2 & 871 & & F-A3 & 2384 \\
\hline F-A1 & 2185 & & F-M3 & 617 \\
\hline F-A2 & 2190 & & A5 & 4054 \\
\hline F-M1 & 575 & & A6 & 1133 \\
\hline F-M2 & 531 & & M6 & 3537 \\
\hline A3 & 3141 & & TOTAL & $\mathbf{4 2 2 9 2}$ \\
\hline & &
\end{tabular}

Note: For the location of each gate, please see Figure 4

The results show that; the main entrances (A1, A4 and A5) that directly face the passengers have the highest demand. According to the simulation results; passengers firstly prefer the entrances at the shortest distance according to their positions in the Haram Area. Then, if the nearest entrance is already crowded, they prefer other entrances to gain time and not to wait long queues.

The next parts show the pedestrian simulation results for all floors one by one. Firstly the $1^{\text {st }}$ concourse floor, then the $2^{\text {nd }}$ concourse floor and finally the platform level will be examined.

\subsection{First Concourse Floor}

The first concourse floor divides the passengers into two directions, Airport and Miqat. The Airport passengers will use the $1^{\text {st }}$ concourse located at minus one level -7.80 meters below the ground level, while the Miqat passengers will use $2^{\text {nd }}$ concourse which is -13.80 meters below the ground level. Then each concourse floor is divided into 3 separate and independent parts for a more efficient control of the passenger circulation. $1^{\text {st }}$ concourse floor mainly serves to the passengers who will go to Airport direction. Only family entrances have access to both Airport and Miqat direction. The green arrows on the plan drawings indicate the direct access to the concourse from on ground main entrances. Figure 6 shows the name of the gates from where the passengers come to the floor and overall pedestrian simulation results. 

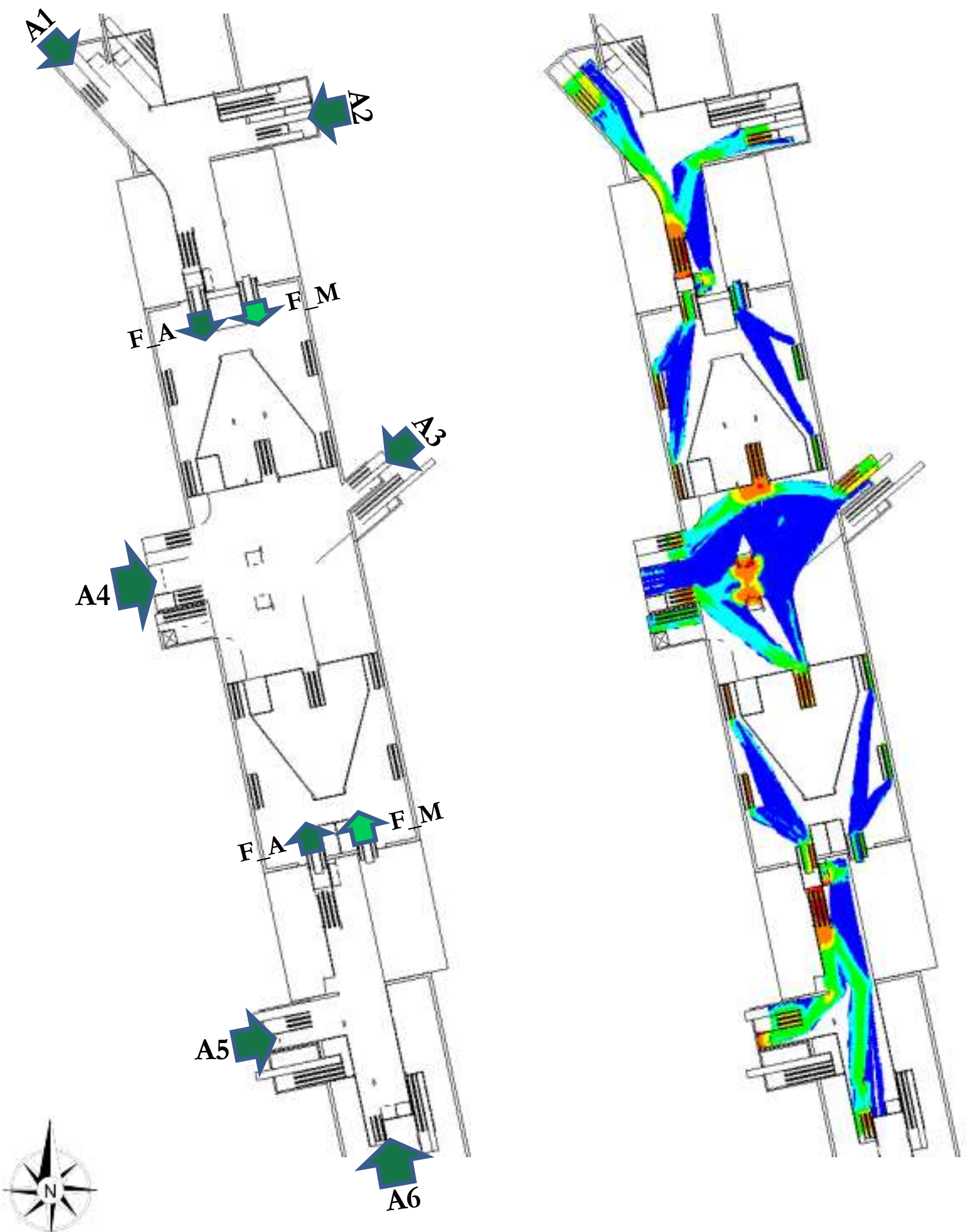

Figure 6: Passenger Density at $1^{\text {st }}$ Concourse Floor

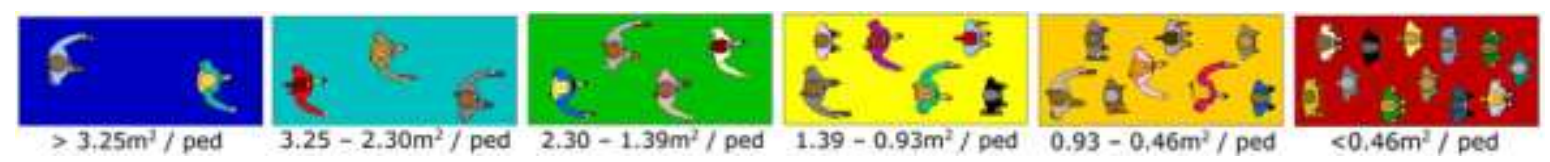


The pedestrian circulation system works very good and passenger flow is fluent in the Airport concourse floor. However there is a little congestion in front of the elevators at some parts, people do not have any dissatisfaction at these areas due to adequate spaces at waiting areas. In front of elevators, people see the escalators going down to the platform level but they prefer to wait elevators for a more comfortable, faster and effortless access to the platform level. In addition there are some little congested areas in front of the escalators at the up and down sides of concourse. Each of these escalators has high demand because of passengers coming from two different entrances but none of them has red color symbolizing very congested and disturbing areas.

According to the simulation results, North side of the $1^{\text {st }}$ concourse floor does not have any problematic area. The red and orange colors on the escalators does not mean danger, it is a result of standing and not moving people on the escalators just like in front of elevators mentioned before. Middle and South sides of the $1^{\text {st }}$ concourse floor does not have any problematic area, too. There are some orange color areas but it is very normal for such a dense station. In addition, these areas do not indicate any danger, just indicates some very short delays because of queues in front of elevators and some escalators.

As a result of detailed view of pedestrian simulation results, it is seen that the airport concourse floor is well functioning and has no serious problem about passenger circulation and flow.

\subsection{Second Concourse Floor}

This floor mainly serves to the passengers who will go to Miqat direction. Due to the low passenger number at Miqat direction, this floor has no congestion or density problem in general.

Figure 7 gives an overall view of the pedestrian simulation results. According to the simulation results, North side of the 2 nd concourse floor does not have any problematic area. As mentioned before, the red and orange colors on the escalators does not mean danger, it is a result of standing and not moving people on the escalators. Middle sand South sides of the 2 nd concourse floor do not have any problematic area. The orange color escalators indicate the Airport direction passengers coming from the 1st concourse floor and going to the platform level by passing 2nd concourse floor. 

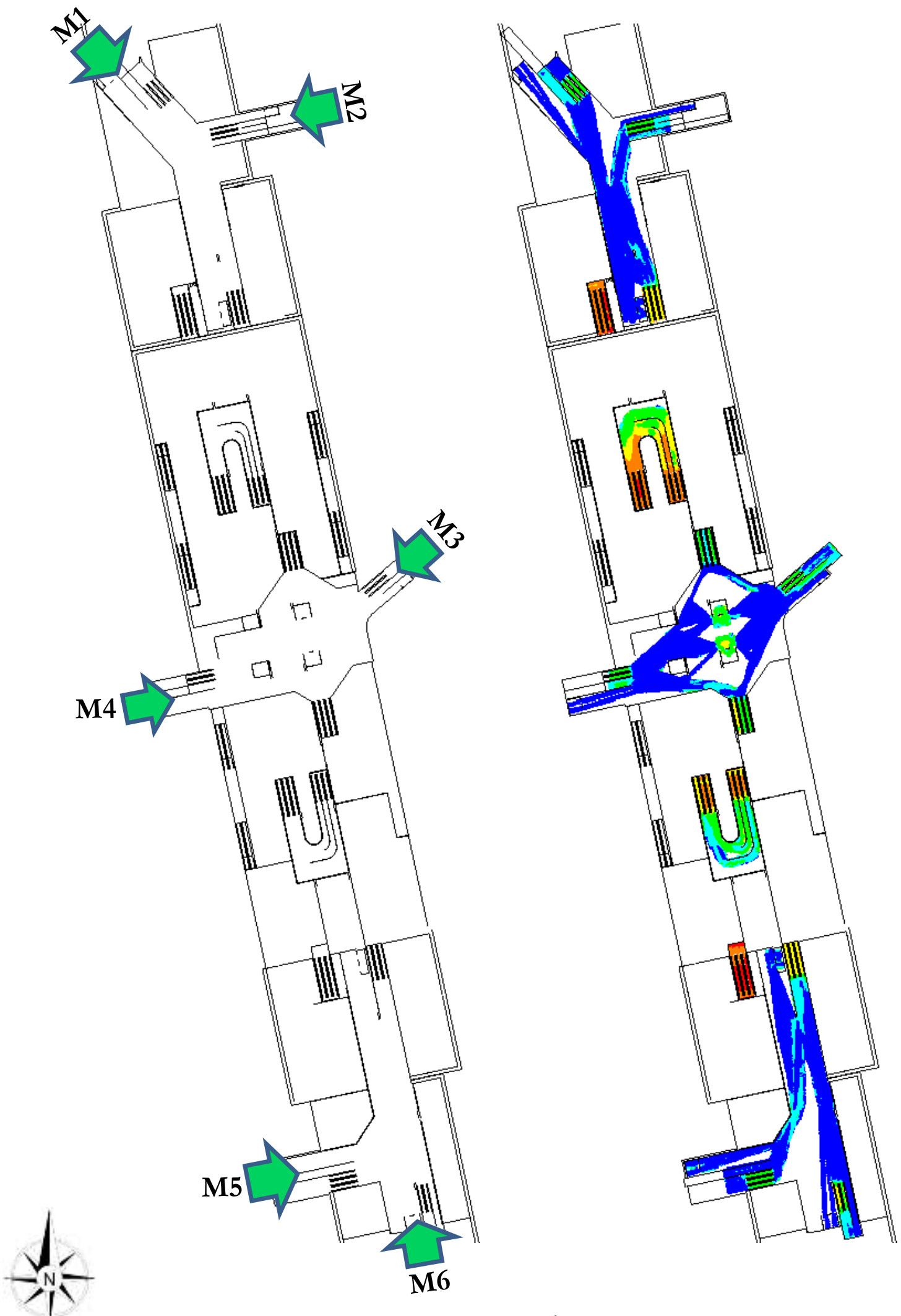

Figure 7: Passenger Density at $2^{\text {nd }}$ Concourse Floor
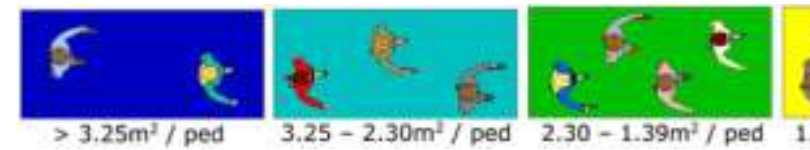
Kırlangıçoğlu, C. (2015). Modeling passenger flows in underground stations. International Journal of Human Sciences, 12(1), 1485-1500. doi: $10.14687 /$ ijhs.v12i1.3275

\subsection{Platform Floor}

According to general station design principles all through the Metro Line 1, platforms must have adequate length and width to accommodate forecasted passengers, and must meet the emergency agreement codes of local civil defense requirements and NFPA 130. They must contain adequate space for passenger movements all through the station including the horizontal and vertical circulation elements leading to transfer among different levels. They must also provide abundant space for waiting passengers.

The platform has been designed to distribute people and the density equally without any conflict or congestion. In Figure 8, yellow rectangles symbolize the trains on the platform. As it is seen, the end of stairs and escalators is nearly $15 \mathrm{~m}$ far away from the first car of the train at both sides. Leaving this transition zone is very important to prevent congestion in front of the escalators because of waiting people on the platform. By this transition zone, the waiting passengers are able to move to the other parts of the platform.

In addition, the landing directions of escalators and stairs have been very carefully designed especially at the Airport side of the platform which has much more passengers than the Miqat platform. Each escalator/stair lands the passenger without any confliction with others. That means, the passengers are distributed all over the platform almost equally. The landing directions are given in Figure 8. The arrows indicate the direction of arrivals coming to the platform level.

The train has boarding option from both sides, one is normal platform and the other one is family platform. Here it is important to prevent the conflict of boarding and alighting passengers. Therefore, firstly the family side doors of the train are opened; the passengers in the train alight. Then the other side doors are opened and all passenger start boarding. In this way, passengers can get on the train from both sides. As a result, the train gets passengers in a shorter time.

According to the simulation results;

- Miqat direction and family platforms do not have any congestion problem because of their low travel demand.

- The airport direction platform seems as having small congested areas especially in front of the train doors. There are some orange color areas but they do not indicate any danger, just indicates waiting people in front of the doors. In addition, people want to get on the train by the shortest way. This causes accumulation right in front of the first car at both sides but does not affect functioning and passenger flow of the platform.

- All passengers alighting leaves the platform before next train arrives and they do not affect the new coming passengers in terms of density. 
Figure 8 gives an overall view of the pedestrian simulation results on the platform level.
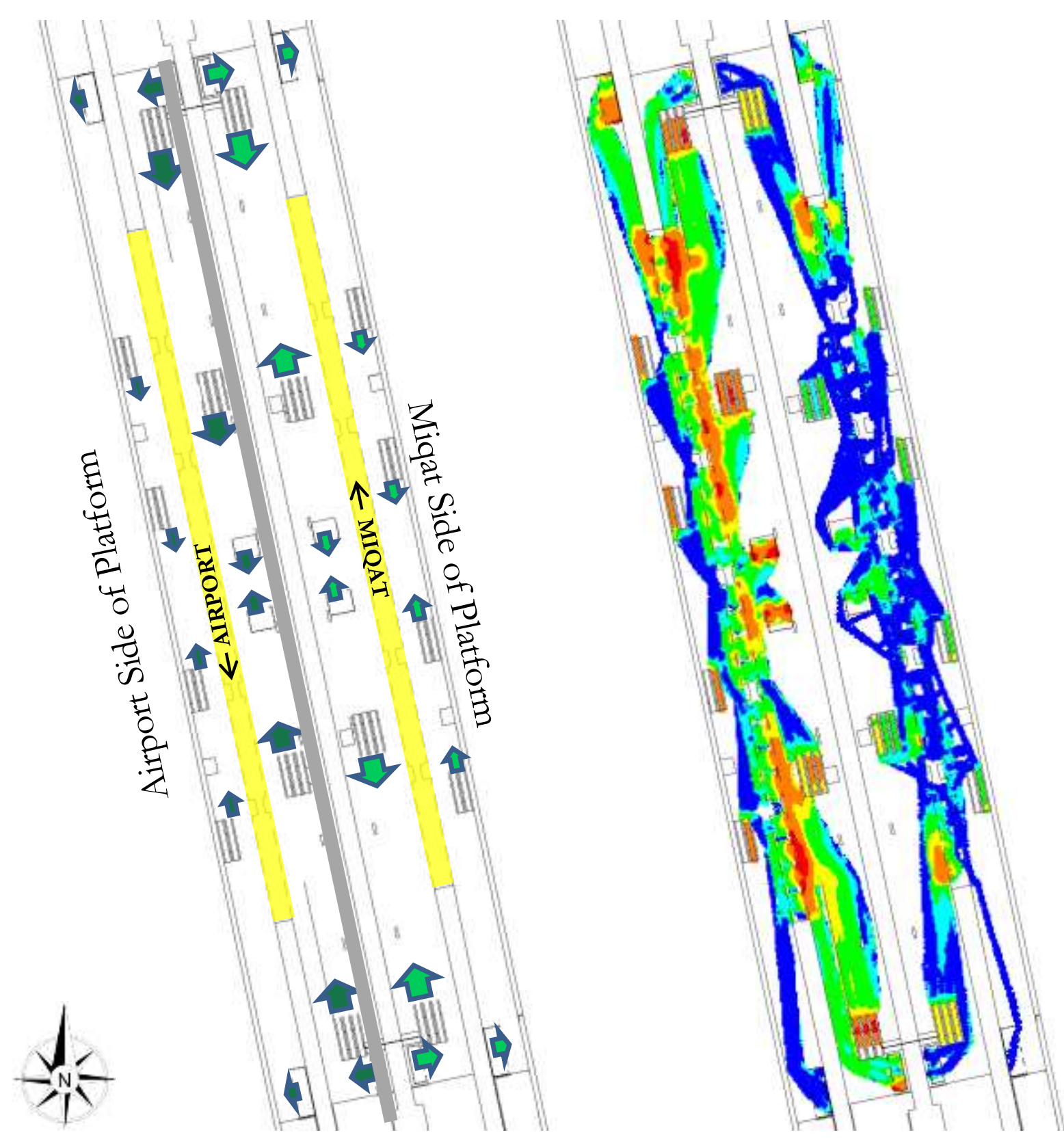

Figure 8: Passenger Density at Platform Level

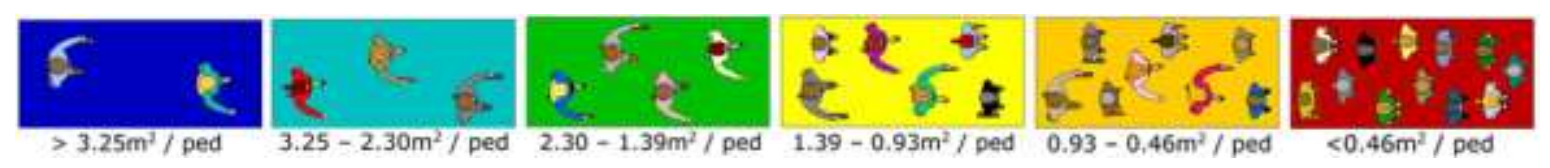

Pedestrian simulation results and flow analyses show that; Haram East Station is accessible, safe, comfortable and well-functioning station in the manner of passenger circulation. Conclusions and recommendations are given in next part in detail. 
Kırlangıçoğlu, C. (2015). Modeling passenger flows in underground stations. International Journal of Human Sciences, 12(1), 1485-1500. doi: $10.14687 /$ ijhs.v12i1.3275

\section{Conclusion}

Modeling the passenger flows has given a new impulse to Haram East Station design process. The first preliminary design was accepted as good enough to meet the circulation requirements of pedestrians for an underground station. Then, the station was tested by the microsimulation software and many failing areas have been detected. In addition to some high level congested areas and bottlenecks, insufficiency of some basic components such as turnstiles, elevators, escalators, stairs and etc. has been detected. After testing a few more alternative designs, the best design providing required levels of service for future demand has been found.

As a result of the study, it is seen that passenger flow in Haram East Station is continuous and fluent for all levels from on ground entrances to the platform level. Circulation routes are clear and free from all kind of unnecessary obstructions. Turnstile, elevator, escalator and stair numbers are adequate to serve all passengers. All spaces, corridors and waiting zones have optimum size and relative arrangement. Platforms have enough capacity to accommodate all waiting passengers in accordance with the train timetable.

Pedestrian simulation technology has been used in this study for the design assessment of an underground metro station and to analyze the passenger circulation problems. It has been a really spectacular experience for the designers to see the future problems at simulation environment before the real world application. Furthermore, it was a really significant period for architects to think about human based designs much more than anytime. This technology may be used for all kind of buildings to understand the nature of human and to serve them better.

\section{References}

Abdelgawad, H., et al. (2012). Microscopic modeling of large-scale pedestrian-vehicle conflicts in the city of Madinah, Saudi Arabia. Journal of Advanced Transportation, 10/2014; 48:507-525.

Fruin, J. J. (1971). Pedestrian Planning and Design. New York: Metropolitan Association of Urban Designers and Environmental Planners, Inc.

KEC. (2012). Knowledge Economic City, Madinah - A Promising Economic Future. Retrieved on April 2, 2015 from http://www.madinahkec.com/en/project/madina

Legion Limited. (2015). Legion - Methodology and Validation. Retrieved on March 30, 2015 from http://www.legion.com/methodology-validation

Rail Safety \& Standards Board. (2004). Managing Large Events and Perturbations at Stations - Pedestrian Flow Modeling Process Definition, Rail Safety \& Standards Board. London, United Kingdom.

Still, G. K. (2013). Crowd Risk Analysis and Crowd Safety. Retrieved on April 2, 2015 from http://www.gkstill.com/CV/PhD/Chapter1.html 